\title{
Association of calcium-stimulated calcitonin values with pathological findings following total thyroidectomy
}

\author{
C. Papadakis (1), I. Keramidas (1), E. Triantafillou(1), F. Kanouta(1), T. Pappa(1), V. Kaltzidou(1), A. Tertipi(1), \\ G. Vecchini(2), D. Papadouli(3), A. Pappas(1) \\ Department of Endocrinology (1), Pathology (2) and Nuclear Medicine (3),Metaxa Anticancer Hospital, Pireaus, Athens, \\ Greece
}

\begin{abstract}
Background and Objectives: Medullary Thyroid Carcinoma (MTC) is a rare neuroendocrine tumor arising from the parafollicular or C cells of the thyroid and it usually secretes calcitonin (CT), in large amounts. MTC accounts for $3-4 \%$ of all thyroid malignancies [1]. It is inherited in $20-30 \%$ of cases where it develops in the setting of MEN 2, induced by germline mutations in REarranged during Transfection (RET) proto-oncogene [2]. Prognosis of MTC is not as favorable as that of other forms of Differentiated Thyroid Carcinoma of follicular origin (DTCf), i.e. Papillary Thyroid Carcinoma (PTC) and Follicular Carcinoma (FTC).

Measurement of basal CT level (bCT) and calcium (or pentagastrin) peak stimulated CT level (psCT) is used in the last decades for an earlier diagnosis, since treatment in less advanced stages is expected to forestall regional or distant metastasis and increase likelihood of radical cure [3]. Based on several studies, it is generally agreed that bCT $>10 \mathrm{pg} / \mathrm{ml}$ necessitates the performance of a CT stimulation test and bCT or psCT $>100 \mathrm{pg} / \mathrm{ml}$ are an indication for total thyroidectomy [4]. However, CT levels may be elevated in patients with $\mathrm{C}$-cell Hyperplasia $(\mathrm{CCH})$ and in this case thyroidectomy might prove unjustified. $\mathrm{CCH}$ shows overlapping bCT and psCT values with MTC and various respective cut-off points have been proposed by a large number of studies in an attempt to preoperatively differentiate MTC from $\mathrm{CCH}$. The objective of this study was to investigate the utility of calcium stimulation test for CT in order to distinguish MTC from CCH preoperatively and to examine the histological findings of thyroidectomy in patients with peak stimulated CT >100 pg/ml.
\end{abstract}

Patients and Methods: A total of 55 patients with thyroid nodules and basal CT levels between 6 and $100 \mathrm{ng} / \mathrm{l}$ had a positive calcium stimulation test (peak CT >100 ng/l) and underwent total thyroidectomy. Their mean age ( \pm SD) was $54.9 \pm 13.6$ years (range 15-76), $58.7 \pm 11.0$ for men (range 37-76) and $50.9 \pm 15.1$ for women (range 15-75). Secondary causes of hypercalcitoninemia (proton pump inhibitor therapy, renal failure, hepatic cirrhosis, atrophic gastritis, hypercalcemia and hypergastrinemia) were ruled out. The calcium stimulation test was performed with the intravenous injection of calcium gluconate in 3 minutes at a dose of $2.3 \mathrm{mg} / \mathrm{kg}$ of elemental calcium. Blood samples were collected at $0,1,2,3$ and 5 minutes after the injection. The only adverse effects were occasional brief ( $<1 \mathrm{~min})$ bouts of nausea, headache, and/or flushing.

Results: Based on surgical histology, 20 patients (36\%) harbored a MTC, 12 women (60\%) and 8 men (40\%). MTC was multifocal in 6 patients and a single focus in the remaining 14. Mean longest tumor diameter was $6.1 \pm 2.9 \mathrm{~mm}$ (median $7 \mathrm{~mm}, \mathrm{range} 0.5-11 \mathrm{~mm})$ with only 3 tumors $\geq 10 \mathrm{~mm}$. Among MTC patients $6(30 \%), 3$ men, had a coexistent DTCf, 5 papillary and 1 follicular thyroid carcinoma. All the 6 DTCf tumors were at a distance from MTC.

The remaining 35 patients $(64 \%)$ had $\mathrm{CCH}$, mostly diffuse and/or focal and occasionally nodular (6 patients). Among $\mathrm{CCH}$ patients, 14 (40\%) had a coexistent PTC. In total, 20 patients (36\%) had DTCf, 12 with a solitary focus (60\%), 7 PTCs and 1 FTC and 8 (40\%) with multifocal PTC. All DTCfs were microcarcinomas with mean longest diameter 2.9 \pm 2.3 mm (median 2.0, range 0.3-9 $\mathrm{mm})$.

Out of 20 patients with MTC, 12 agreed to perform RET gene analysis and 7 were diagnosed as Multiple Endocrine Neoplasia (MEN) Type $2 \mathrm{~A}$ with 6 patients harboring the $\mathrm{G} 533 \mathrm{C}$ mutation in RET exon 8 , a frequent mutation in our country [5) and 1 patient with the mutation $\mathrm{C} 634 \mathrm{R}$ in exon 11. Among the $7 \mathrm{MEN} 2 \mathrm{~A}$ patients, one patient with the $\mathrm{G}_{533} \mathrm{C}$ mutation had a coexistent PTC.

In ROC curve the best cut-off point of bCT that differentiated MTC patients from CCH patients was $17.4 \mathrm{pg} / \mathrm{ml}$, sensitivity $80 \%$, specificity 63\%, (AUC 0.80, P < 0.001, Cl 0.68-0.92), with positive predictive value (PPV) $55 \%$ and NPV $85 \%$. The best cut-off for psCT was found at $452 \mathrm{pg} / \mathrm{ml}$ with sensitivity $85 \%$, specificity $86 \%$, (AUC $0.88, \mathrm{P}<0.001, \mathrm{Cl} 0.77-0.98$ ), PPV 59\% and NPV $79 \%$. Lastly, for the $\triangle C T$ value ROC curve gave as the best cut-off the $412 \mathrm{pg} / \mathrm{ml}$, sensitivity $85 \%$, specificity $86 \%(\mathrm{AUC} 0.87, \mathrm{P}<0.001, \mathrm{Cl}$ $0.77-0.98)$, PPV $59 \%$ and NPV $79 \%$

Conclusion: A large percentage of MTC may be identified by peak stimulated CT levels $>100$ pg/ml preoperatively, but overlapping calcitonin levels between MTC and CCH reduce the accuracy of the test. Remarkably, many patients with peak stimulated CT levels $>100 \mathrm{pg} / \mathrm{ml}$ harbor a DTCf. A probable association between C-cell disease and DTCf needs further examination.

\section{References}

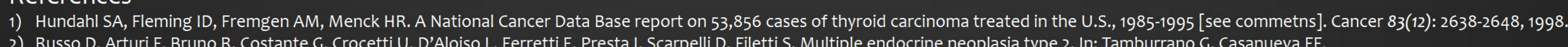
2) Russo D, Arturi F, Bruno R, Costante G, Crocetti U, D'Aloiso L, Ferretti E, Presta I, Scarpelli D, Filetti S, Multiple endocrine neoplasia type 2. In: Tamburrano G, Casanueva FF,

Baldelli R, eds. Update in neuroendocrinology. From basic research to clinical practice. Rome: Pubblicazioni Medico Scientifiche; p. 292-296, 2004,

3) Elisei R, Bottici V, Luchetti F, Di Coscio G, Romei C, Grasso L, et al. Impact of routine measurement of serum calcitonin on the diagnosis and outcome of medullary thyroid cancer:

experience in 10,864 patients with nodular thyroid disorders. J Clin Endocrinol Metab 89(1): 163-168, 2004.

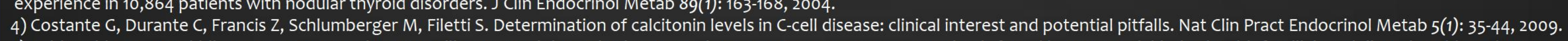

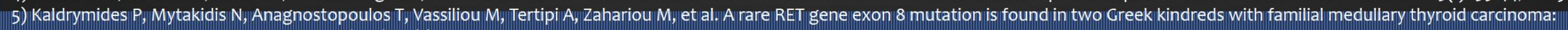
implications for screening. Clin Endocrinol (Oxf) 64(5): $561-566,2006$. 